\title{
A escolha da via de parto e a autonomia das mulheres no Brasil: uma revisão integrativa
}

\author{
The choice of the mode of delivery and the autonomy of women in \\ Brazil: an integrative review
}

Nathalia Fernanda Fernandes da Rocha', Jaqueline Ferreira1

DOI: 10.1590/0103-1104202012521

RESUMO O artigo trata de uma revisão integrativa sobre os determinantes que envolvem a escolha da via de parto no Brasil. Foram selecionados e analisados 15 documentos evidenciando a escolha da via de parto sob a perspectiva da autonomia das mulheres e a prevalência da cirurgia cesariana. O estudo revelou três categorias para análise: perfil socioeconômico das mulheres inseridas no atendimento público e privado, relação assimétrica entre os profissionais de saúde e a paciente e aspectos socioculturais que envolvem a escolha da cesárea comumente conhecidos como a 'cultura da cesárea'. Os achados revelaram que aspectos como acesso aos serviços, violência obstétrica e informação às mulheres sobre as vias de parto são preponderantes. Quanto à autonomia das mulheres, elas não se sentem participativas ou respeitadas na decisão. Ademais, espera-se contribuir para a discussão sobre a elaboração de medidas que garantam o direito da mulher quanto à sua participação na escolha da via de parto, possibilitando a escolha informada e resgatando a autonomia das mulheres em seu processo gravídico-puerperal.

PALAVRAS-CHAVE Parto. Obstetrícia. Cesárea. Medicalização. Saúde da mulher.

\begin{abstract}
The article deals with an integrative review on the determinants that involve the choice of the mode of delivery in Brazil. Fifteen documents were selected and analyzed showing the choice of the mode of delivery from the perspective of women's autonomy and the prevalence of cesarean surgery. The study revealed three categories for analysis: socioeconomic profile of women in public and private care, asymmetrical relationship between health professionals and parturient and sociocultural aspects that involve the choice of cesarean section commonly known as the 'culture of cesarean section'. The findings revealed that aspects such as access to services, obstetric violence, and information to women about the mode of delivery are predominant. As for the autonomy of women, they do not feel participatory or respected in the decision. Furthermore, it is expected to contribute to the discussion on the elaboration of measures that guarantee the woman's right regarding her participation in the choice of the mode of delivery, enabling the informed choice and rescuing the autonomy of women in their pregnancy-puerperal process.
\end{abstract}

KEYWORDS Parturition. Obstetrics. Cesarean section. Medicalization. Women's health.

1 Universidade Federal do 


\section{Introdução}

As práticas de parto no contexto brasileiro têm sido pauta importante nas discussões em saúde pública nos últimos 30 anos devido à magnitude da mortalidade materna e neonatal e ao uso indiscriminado de tecnologias na assistência'. Nas propostas de reformulação do cenário, buscam-se o cuidado centrado na mulher e o uso das tecnologias disponíveis de forma menos intervencionista e mais humanizada.

O modelo obstétrico brasileiro vigente, caracterizado pelas altas taxas de cesarianas, tem sido apontado como causa dos elevados índices de óbito materno e neonatal ${ }^{2}$. Esse fenômeno característico de intensa medicalização do processo do nascimento, resultado do desenvolvimento tecnológico, mas com persistência de ressaltados números de morbimortalidade materna e perinatal, é definido por Diniz ${ }^{3}$ como paradoxo perinatal brasileiro.

Por outro lado, estudos com diversas metodologias apontam a insatisfação de mulheres acerca da via de parto ${ }^{4-9}$. Tal demanda justifica o aumento de mulheres de condições socioeconômicas diferenciadas em busca de partos domiciliares ou instituições que respeitem o modelo de humanização do parto e nascimento proposto pelo Ministério da Saúde ${ }^{7}$. Isso indica a relevância de pesquisas e discussão sobre os fatores que envolvem a escolha da via de parto das mulheres no Brasil.

Dessa forma, esta pesquisa objetivou, por meio de uma revisão integrativa de literatura, apresentar e discutir quais os determinantes e como ocorre a escolha da via de parto, levando em conta o direito de autonomia das mulheres.

\section{Metodologia}

O presente estudo trata-se de uma revisão integrativa acerca da escolha da via de parto no modelo de atenção obstétrica brasileira, considerando o contexto de medicalização da saúde vivido no Brasil. A escolha pela pesquisa neste formato surgiu da necessidade de sintetizar o conhecimento publicado acerca da temática, proporcionando uma visão que possibilite o entendimento e a discussão do assunto.

Considera-se que é possível elaborar uma revisão integrativa com diferentes finalidades, logo, a multiplicidade da composição da amostra proporciona um quadro completo de materiais que permite formular um retrato compreensivo do tema, possibilitando o aprofundamento e abrangência das conclusões da revisão ${ }^{10}$.

Algumas etapas devem ser seguidas para o desenvolvimento da revisão integrativa. São elas: a elaboração da pergunta/problemática, a coleta bibliográfica, a classificação dos dados, a análise e a discussão dos estudos incluídos e os resultados"11.

Conforme já referido, o tema e pergunta norteadora deste estudo é como ocorre a escolha da via de parto e como se insere a autonomia da gestante quanto ao próprio cuidado nesse cenário, tendo em vista o alto índice de cesáreas realizadas no Brasil.

Nesse sentido, foi realizada uma pesquisa bibliográfica no período de agosto a outubro de 2018. As bases de dados utilizadas foram Scientific Electronic Library Online (SciELO), na modalidade integrada ao Portal Regional da Biblioteca Virtual em Saúde (BVS), utilizando dois descritores ('medicalização' e 'parto'), assim como seus sinônimos ('aliviamento', 'parição', 'nascimento', 'parturição'), visando ampliação de busca pelos estudos. Os descritores foram utilizados no intuito de obter uma visão contextualizada sobre o tema. As plataformas internacionais Scopus e Medline foram consultadas, porém, foram desconsideradas da pesquisa por não apresentarem resultados relevantes no âmbito brasileiro.

Utilizaram-se os filtros 'texto completo' e o idioma em português. Após a análise dos títulos e dos resumos, parte dos documentos foi desconsiderada por não se encaixar na temática selecionada.

Os critérios de inclusão utilizados foram: textos completos disponíveis nas plataformas com o tema pertinente à proposta do estudo. 
Após leitura dos resumos, configuraram-se, como critério de exclusão, os trabalhos que não se adequaram ao esperado, assim como as duplicatas e os documentos que não fossem em formato de artigo e tese.

Os documentos selecionados foram publicados no período de 2003 a 2017, abordando o contexto das regiões brasileiras (especialmente as áreas urbanas); e foram agrupados em forma de quadro 1, organizados nas colunas: referência/título; metodologia/área de publicação; e proposta do estudo.

Quadro 1. Referência, metodologia, área e proposta dos artigos e teses identificados

№ Referência / Título

1 Cesar JA, Sauer JP, Carlotto K, et al. Cesariana a pedido: um estudo de base populacional no extremo Sul do Brasil. Rev. Bras. Saúde Mater. Infant. 2017; 17(1):99-105.

2 Souza AB, Silva LC, Alves RN, et al. Fatores associados à ocorrência de violência obstétrica institucional: uma revisão integrativa da literatura. Rev. Ciênc. Méd. 2016; 25(3):115-128.

3 Oliveira VJ. O sensível e o insensível na sala de parto: interdiscursos de profissionais de saúde e mulheres [tese]. Belo Horizonte: Escola de Enfermagem, Universidade Federal de Minas Gerais; 2016. 160 p.

4 Oliveira VJ, Penna CMM. Every birth is a story: process of choosing the route of delivery. Rev. Bras. Enferm. 2018; 71(3):1228-1236.

5 Oliveira VJ, Penna CMM. O discurso da violência obstétrica na voz das mulheres e dos profissionais de saúde. Texto Contexto Enferm. 2017; 26(2):2-10.

6 Leão MRC, Riesco MLG, Schneck CA, et al. Reflexões sobre o excesso de cesarianas no Brasil e a autonomia das mulheres. Ciênc. Saúde Colet. 2013; 18(8):2395-2400.

7 Cabral FB, Hirt LM, Van der Sand ICP. Atendimento pré-natal na ótica de puérperas: da medicalização à fragmentação do cuidado. Rev. esc. enferm. USP. 2013; 47(2):281-287

8 Freire NC, Nunes IM, Almeida MS, et al. Parto normal ou cesárea? A decisão na voz das mulheres. Rev Baiana Enf. 2011; 25(3):237-247.

9 Pires D, Fertonani HP, Conill EM. et al. A influência da assistência profissional em saúde na escolha do tipo de parto: um olhar sócio antropológico na saúde suplementar brasileira. Rev. Bras. Saúde Mater. Infant. 2010; 10(2):191-197.

10 Porto AMF, Amorim MMR, Souza ASR. Assistência do primeiro período do trabalho de parto baseada em evidências. Femina. 2010; 38(10):527-537.

\section{Metodologia / Área de Proposta do estudo publicação}

Quantitativo / Saúde Materno-Infantil

Revisão integrativa / Psicologia

Qualitativo / Enfermagem

Qualitativo / Enfermagem

Qualitativo / Enfermagem

Qualitativo / Saúde

Coletiva

Qualitativo e exploratório-descritivo / Enfermagem

Qualitativa / Enfermagem

Qualitativo e exploratório-descritivo / Saúde Materno-Infantil

Revisão sistemática / Medicina
Medir a prevalência e identificar fatores associados à ocorrência de cesarianas a pedido no município de Rio Grande, RS.

Realizar revisão integrativa da literatura sobre os fatores associados à ocorrência de violência obstétrica institucional e apresentar as principais evidências encontradas nos artigos selecionados.

Analisar os discursos sobre a assistência ao parto na perspectiva de mulheres/puérperas e profissionais de saúde de uma rede pública, considerando as interações vivenciadas durante o trabalho de parto e parto.

Analisar os discursos sobre escolha da via de parto na perspectiva de mulheres e profissionais de saúde de uma rede pública.

Analisar os discursos de mulheres e profissionais de saúde sobre a assistência ao parto, considerando as situações vivenciadas e as interações construídas entre eles durante o trabalho de parto e parto.

Refletir sobre o excesso de cesarianas no Brasil em uma perspectiva crítica e propositiva.

Conhecer a percepção de puérperas sobre atendimento em serviço de pré-natal.

Descrever o processo de tomada de decisão das mulheres sobre a via de parto.

Focalizar, por meio de um recorte de uma pesquisa multicêntrica realizada em três capitais da Região Sul, as experiências de usuárias da rede suplementar, buscando contribuir para a compreensão da influência da assistência profissional na escolha do tipo de parto realizado nesse segmento.

Oferecer recomendações baseadas em evidências para a assistência ao primeiro período do trabalho de parto em gestacõos de baixo risco, contemplando o diagnóstico do trabalho de parto e recomendações, como intervenções maternas, propedêutica fetal, utilização do partograma e manejo ativo do trabalho de parto. 
Quadro 1. (cont.)

\begin{tabular}{|c|c|c|c|}
\hline № & Referência / Título & $\begin{array}{l}\text { Metodologia / Área de } \\
\text { publicação }\end{array}$ & Proposta do estudo \\
\hline 11 & $\begin{array}{l}\text { Barbosa GP, Giffin K, Angulo-Tuesta A, et al. Par- } \\
\text { to cesáreo: quem o deseja? Em quais circunstân- } \\
\text { cias? Cad. Saúde Pública. 2003; 19(6):1611-1620. }\end{array}$ & $\begin{array}{l}\text { Quantitativo-qualitativo } \\
\text { / Saúde Pública }\end{array}$ & $\begin{array}{l}\text { Investigar a existência de uma 'cultura de cesárea', ou preferência } \\
\text { por esse tipo de parto, por meio de uma amostra de } 909 \text { puér- } \\
\text { peras ( } 454 \text { vaginais e } 455 \text { cesáreos) em duas maternidades do } \\
\text { município do Rio de Janeiro. }\end{array}$ \\
\hline 12 & $\begin{array}{l}\text { Nakano AR, Bonan C, Teixeira LA. A normaliza- } \\
\text { ção da cesárea como modo de nascer: cultura } \\
\text { material do parto em maternidades privadas no } \\
\text { Sudeste do Brasil. Physis. 2015; 25(3):885-904. }\end{array}$ & $\begin{array}{l}\text { Qualitativa / Saúde } \\
\text { Coletiva }\end{array}$ & $\begin{array}{l}\text { Discutir o desenvolvimento de uma cultura material em torno do } \\
\text { parto e do nascimento em um contexto de utilização maciça de } \\
\text { inovações tecnocientíficas e explorar a hipótese da normalização } \\
\text { da cesariana como modo de nascer, por meio da análise de relatos } \\
\text { de mulheres que realizaram cesáreas em maternidades privadas } \\
\text { do Rio de Janeiro e São Paulo. }\end{array}$ \\
\hline 13 & $\begin{array}{l}\text { Gama AS, Giffin KM, Angulo-Tuesta A, et al. } \\
\text { Representações e experiências das mulheres } \\
\text { sobre a assistência ao parto vaginal e cesárea } \\
\text { em maternidades pública e privada. Cad. Saúde } \\
\text { Pública. 2009; 25(11):2480-2488. }\end{array}$ & $\begin{array}{l}\text { Qualitativa / Saúde } \\
\text { Pública }\end{array}$ & $\begin{array}{l}\text { Analisar as diferentes representações e experiências das mulheres } \\
\text { quanto ao parto vaginal e cesárea, bem como investigar a natureza } \\
\text { das relações profissionais de saúde/usuárias no contexto insti- } \\
\text { tucional em que estão inseridas, supondo que contribuem para a } \\
\text { manutenção de altas taxas de cesárea e de outras intervenções no } \\
\text { parto, nos diferentes modelos de organização dos serviços: públi- } \\
\text { co, conveniado com o SUS e privado. }\end{array}$ \\
\hline 14 & $\begin{array}{l}\text { Narchi NZ, Cruz EF, Gonçalves R. O papel das } \\
\text { obstetrizes e enfermeiras obstetras na promoção } \\
\text { da maternidade segura no Brasil. Ciênc. Saúde } \\
\text { coletiva. 2013; 18(4):1059-1068. }\end{array}$ & $\begin{array}{l}\text { Qualitativa / Saúde } \\
\text { Coletiva }\end{array}$ & $\begin{array}{l}\text { Oferecer subsídios teóricos que sustentem a proposta de que a } \\
\text { promoção da maternidade segura requer a efetiva participação de } \\
\text { obstetrizes e enfermeiras obstetras, profissionais que, a partir da } \\
\text { perspectiva da promoção da saúde, podem colaborar na consti- } \\
\text { tuição de uma rede efetiva de cuidados, cuja premissa básica seja } \\
\text { a atenção humanizada e baseada em evidências científicas, a fim } \\
\text { de melhorar a experiência da mulher e da família no processo de } \\
\text { gestação, parto e pós-parto. }\end{array}$ \\
\hline 15 & $\begin{array}{l}\text { Diniz CSG. Entre a técnica e os direitos huma- } \\
\text { nos: possibilidades e limites da humanização da } \\
\text { assistência ao parto [tese]. São Paulo: Faculdade } \\
\text { de Medicina, Universidade de São Paulo; } 2001 . \\
255 \text { p. }\end{array}$ & $\begin{array}{l}\text { Qualitativa / Medicina } \\
\text { Preventiva }\end{array}$ & $\begin{array}{l}\text { Estudar as possibilidades e os limites da implantação de propostas } \\
\text { de reorganização da assistência ao parto em maternidades da ci- } \\
\text { dade de São Paulo, mediante estudo de caso, orientados pela ideia } \\
\text { de humanização e de medicina perinatal baseada na evidência } \\
\text { científica. Os achados sugerem que entre os fatores que podem } \\
\text { tornar possível ou limitada esta humanização do parto estão a } \\
\text { adequação do acesso aos leitos, da comunicação entre os sujeitos, } \\
\text { do manejo da dor e dos tempos no parto; assim como a presença } \\
\text { ou não de uma cultura de reconhecimento pelos profissionais } \\
\text { tanto da evidência científica quanto dos direitos das mulheres. }\end{array}$ \\
\hline
\end{tabular}

Fonte: Elaboração própria.

\section{Resultados e discussões}

\author{
A busca resultou em 538 documentos. Após as \\ análises, foram selecionados 15 documentos \\ para compor a revisão. A grande maioria dos \\ estudos é qualitativa (11). As áreas preponde- \\ rantes dos artigos encontrados foram saúde \\ coletiva/pública (6) e enfermagem (5). As \\ áreas de saúde coletiva/pública e enferma- \\ gem predominam na elaboração dos artigos \\ analisados, revelando como elas têm como \\ suas prioridades de estudos questões como
}

medicalização e humanização da assistência. No caso da enfermagem, os estudos refletem como essa categoria profissional é particularmente tocada por essas questões, o que justifica seus investimentos nesse tema.

Após leitura integral e análise dos documentos, foram definidas três categorias de análise que permeiam a escolha da via de parto e autonomia das mulheres: perfil socioeconômico das mulheres inseridas no atendimento público e privado; relação assimétrica entre os profissionais de saúde e a paciente; 
e aspectos socioculturais que envolvem a escolha da cesárea comumente conhecidos como a 'cultura da cesárea'.

\section{Perfil socioeconômico das mulheres inseridas no atendimento público e privado}

Para compreender o cenário de assistência ao parto no Brasil, é importante identificar os perfis socioeconômicos dos atores envolvidos, em que contexto se inserem, quais são as características predominantes de cada serviço e suas disparidades. Os trabalhos que abordaram essa perspectiva socioeconômica indicam, por meio de métodos quantitativos e qualitativos, o perfil das mulheres atendidas nas instituições estudadas. De modo geral, no setor público, predominam mulheres que se declaram pardas ou negras, com baixo grau de escolaridade, baixo poder aquisitivo, ao passo que, no setor suplementar e privado, predominam as mulheres brancas, com alto grau de escolaridade e alto poder aquisitivo. As idades das entrevistadas em ambos os setores apresentam variação, sendo possível afirmar que, no setor público, as mulheres engravidam mais cedo, na faixa etária entre 18 anos e 30 anos; e no setor privado, a maioria situa-se na entre 30 anos e 40 anos 9,12-19.

Não obstante, a maioria das mulheres que busca atendimento no setor privado é atendida pelo mesmo médico durante todo seu pré-natal e parto. No entanto, a assistência na rede privada durante a gestação e parto não garante que a mulher receba mais informação e se sinta mais empoderada, apesar da condição de pagante ${ }^{9,15}$.

Os resultados do artigo de Pires ${ }^{16}$ mostraram que, em um grupo de mulheres com melhor renda e escolaridade, verifica-se altíssima incidência de cesarianas. O estudo de Nakano ${ }^{18}$ avaliou a normalização da cesárea como modo de nascer, realizando um estudo entre mulheres do setor privado, de classe alta, que residiam nas áreas nobres do Rio de Janeiro (Zona Sul e Barra da Tijuca especificamente).
A maioria das mulheres entrevistadas (73\%, $\mathrm{n}=24$ ) já havia decidido o parto por via cirúrgica, mesmo antes de engravidar; e as demais, quase a totalidade, fizeram essa opção logo no início da gestação. Para essas mulheres, aspectos como conforto, privacidade, praticidade como no caso do agendamento da data do parto por exemplo - e atenção personalizada são indispensáveis no ciclo gravídico-puerperal, e acreditam que isso não é disponibilizado no setor público, supervalorizando os recursos materiais e estruturais. Os autores ressaltam que, na preferência da cesariana, nenhuma mulher acompanhada no setor suplementar cogitou a possibilidade de recusa médica.

Por outro lado, como referem Gama ${ }^{19}$, recentemente, há um movimento em que as informantes do setor suplementar estão buscando cada vez mais o parto normal por valorizarem as práticas mais 'naturais'. Percebe-se, então, que há dois movimentos nesse grupo social: o das mulheres que relatam medo ou desgosto pelo parto normal e o daquelas que se sentiram frustradas por não o terem realizado.

Outros trabalhos ${ }^{8,9}$ mostram que as mulheres mais pobres do setor público não são empoderadas no pré-natal, não recebem informação necessária e têm medo de interpelar os profissionais de saúde sobre o parto. Todavia, são elas que sofrem menos intervenção cesariana, mas, por outro lado, sofrem mais procedimentos dolorosos, como a aceleração do trabalho de parto e de baixo uso de analgesia obstétrica.

\section{Relação assimétrica entre os profissionais de saúde e a paciente}

A maioria dos artigos integrantes da revisão abordou a relação médico-paciente como um fator essencial na determinação da via de parto das mulheres no Brasil13,14,16,17,19-22. Nota-se o médico como ator principal no cenário do parto, enquanto a mulher se torna coadjuvante, já que a medicalização tornou o parto um evento médico, no qual a parturiente não se sente ativa no processo de dar à luz o seu 
filho 20 . Essa relação assimétrica é permeada pela supervalorização do saber técnico dotado pela equipe, que presume o não saber da mulher, desconsiderando sua capacidade de participar do próprio processo fisiológico. Logo, no contexto vivido pelas mulheres nas maternidades do Brasil, os sentimentos de angústia e temor são frequentes entre as usuárias, pois o cuidado recebido vai contra o cuidado esperado ${ }^{15}$.

Há uma grande discussão em torno do respeito à autonomia das mulheres envolvendo o Conselho Federal de Medicina, que defende o direito à autonomia das mulheres em relação à cesariana a pedido ${ }^{23}$. No sentido oposto, as mulheres sentem-se impossibilitadas de questionar a necessidade ou não da cesárea, diante da postura hostil ou autoritária dos profissionais de saúde ${ }^{19,21}$. Diante desses elementos, a Organização Mundial da Saúde (OMS) estimula, desde 1986, o plano de parto. Essa proposta objetiva ser uma "ferramenta educativa que provoca rupturas simbólicas na relação hierárquica das mulheres com os profissionais" ${ }^{24}$, pois encoraja as gestantes a buscarem informações sobre o processo do parto e nascimento, baseando-se em evidências científicas e preferências da gestante. Por se tratar de um documento, ele deve ser assinado pelos profissionais responsáveis pelo cuidado da mulher na hora do parto, e deve ser anexado ao seu prontuário. Apesar de ser um meio de estimular o protagonismo da mulher, não é uma prática largamente difundida e até mesmo recentemente recusada pela atenção obstétrica brasileira, não havendo consenso entre o cuidado que as mulheres devem esperar e o cuidado que os profissionais se propõem a oferecer. Ainda que outros profissionais possam reconhecer a importância do plano de parto da mulher, a postura verticalizada do cuidado prestado na hora do parto faz com que o obstetra, que, na maioria das instituições brasileiras, é quem atende as parturientes, não considere as escolhas da mulher, podendo, inclusive, resultar em retaliação e negligência ${ }^{24}$.
O artigo de Souza et al. ${ }^{20}$ constata que os próprios profissionais reconhecem as práticas discriminatórias e desrespeitosas, consideradas como violência obstétrica, no cotidiano da assistência à mulher. $\mathrm{O}$ impacto da violência obstétrica vai desde a perspectiva macro até a micro, uma vez que desfavorece o vínculo e a promoção da saúde. Isso contribui para que o parto, no imaginário das mulheres, seja necessariamente associado à dor e ao sofrimento, naturalizando a violência. Consequentemente, tamanha proporção contribui para o aumento e para a manutenção das taxas de mortalidade materna e neonatal devido ao excesso de intervenções desnecessárias e a uma assistência que favorece a negligência, a imprudência e a imperícia.

O artigo de Oliveira e Penna ${ }^{13}$ conclui que, apesar de algumas mulheres assumirem a cesárea como escolha inicial, elas não estão sendo orientadas das vantagens e desvantagens da via de parto adequadamente e não estão conscientes dos riscos da prematuridade e outras implicações. Observa-se, na fala das mulheres, ao justificarem a submissão à cesárea por indicação médica, a incorporação de argumentos técnicos do campo da saúde, como parada da dilatação, rompimento uterino, infecção e perda de líquido.

Conforme o decorrer da gestação, as indicações para a cesárea vão surgindo: 'bebê grande', 'bacia pequena', 'cordão enrolado', 'bebê atravessado', 'pouco líquido', 'muito líquido', 'dificuldade de dilatação', diagnosticados pelo médico e reforçados por relatos de pessoas do meio social da gestante sobre partos difíceis. $\mathrm{O}$ artigo de Oliveira e Pena ${ }^{13}$ identifica, no discurso dos médicos entrevistados, o desejo de que o parto evolua e aconteça o mais rápido possível, para que a equipe médica possa dar sequência ao atendimento de outras mulheres ou para realizar outras atividades, o que pode justificar um atendimento intervencionista e cesarista. A assistência ao parto organizada como uma linha de montagem ${ }^{25}$, na qual para cada estágio do parto a mulher é transferida para um setor da maternidade, 
estipulando-se tempo para a conclusão de cada etapa, desrespeita a fisiologia do parto. Nesse sentido, fatores como indisponibilidade de leitos diante da grande demanda, equipe reduzida, metas institucionais a serem alcançadas, conveniência do médico aparecem nos estudos como possíveis justificativas para o modelo tecnocrático vigente de atenção ao parto no Brasil19,16,19-21,26,27. Esse modelo institui que as mulheres, ao darem entrada na maternidade, são obrigadas a entregar seus pertences, despindo-se de seus trajes, são imobilizadas em diversos momentos, restritas de água e alimentos; e, muitas vezes, seu direito de ter acompanhante é violado $22,26,27$.

Sobre a escolha da via de parto, o artigo de Barbosa ${ }^{\mathbf{1 7}}$ apresenta que, em sua pesquisa, a maioria absoluta das mulheres $(82,9 \%)$ informou não ter demandado a cesariana, tanto aquelas que tiveram parto vaginal (81\%) como as que foram submetidas ao parto operatório (85\%), considerando o tamanho da amostra igual a 909 entrevistadas, distribuídas no setor público e privado.

Grande parte dos estudos identifica que a maioria das mulheres apresenta preferência a uma via de parto - seja vaginal ou cirúrgica -, porém, conformam-se quando o parto não acontece como esperado, comprovando que elas não participaram ou não se sentem ativas/respeitadas na escolha da sua via de parto 9,13,16,17,19-21,26. Para muitas mulheres, o 'destino' ou a ideia de que 'foi Deus quem quis assim' é o que opera na decisão dos médicos sobre a forma que se dará o parto. Na perspectiva do médico, a assistência ao parto vai além do saber técnico e envolve questões imprevisíveis, que fogem à regra dos protocolos das instituições ${ }^{\mathbf{1 3}}$. Percebe-se que a escolha da via de parto é muito mais do que um desejo por parte das mulheres, pois depende do acesso às orientações durante o período pré-natal e envolve aspectos familiares e culturais ${ }^{13,15}$.

No que diz respeito à satisfação da mulher quanto ao próprio parto ${ }^{\mathbf{1 5}, 16,20}$, os estudos relatam que um número considerável de mulheres sentiu insatisfação quanto à a sua experiência de parto pela impotência diante das decisões médicas e da falta de informações adequadas. $\mathrm{O}$ artigo de Gama ${ }^{19}$, ao abordar a satisfação em relação às informações recebidas durante a gestação e parto entre as mulheres, constatou que as usuárias do setor privado se sentiram mais satisfeitas devido ao fato de terem feito o pré-natal e o parto com o mesmo obstetra, o que trouxe maior sensação de segurança.

Destaca-se a importância do pré-natal nesse processo, por ser o momento ideal para a promoção e educação em saúde, a partir das consultas e encontros com os serviços. A descontinuidade da atenção e a fragmentação do vínculo com os profissionais durante o pré-natal são apontadas como contribuintes para a insatisfação das mulheres durante sua gestação ${ }^{14}$.

Argumentos relacionados com os critérios técnicos em contraposição ao desejo das mulheres de não sofrer desnecessariamente no parto normal13 ${ }^{13}$ sao presentes no discurso médico, e ressaltam a importância de debater sobre a qualidade do parto normal oferecido nas instituições brasileiras. É válido, inclusive, pensar na classificação de 'parto normal': a mudança de cenários, atores, cuidados e paradigmas na assistência ao parto ao longo dos tempos permite ainda que o parto vaginal seja chamado de 'normal', mesmo que se configure de forma completamente diferente no período pré-medicalização e pós-medicalização? Autores como Diniz ${ }^{25}$ questionam que o que consideramos como 'normal' é o parto vaginal dirigido, ou seja, aquele que segue as rotinas hospitalares, que ocorre com a mulher imobilizada ou semi-imobilizada na maca ou leito, privada de alimentação e ingesta de líquidos, usando drogas para a indução ou aceleração do parto, parindo deitada de barriga para cima e as pernas levantadas, com eventual uso de fórceps e, rotineiramente, com a realização de episiotomia. Assim, a discussão sobre a qualidade do parto normal no Brasil deve ser considerada tão relevante quanto as taxas alarmantes de cesariana, uma vez que ambas as questões interferem nos indicadores de mortalidade materna e neonatal, assim como determinam o 
cenário de violência obstétrica. Nesse sentido, o desrespeito à autonomia, a realização de intervenções sem a devida explicação e consentimento, a falta de informação, assim como as 'falsas' informações às gestantes, como, por exemplo, cesarianas indicadas por motivos inadequados ou irreais, entre outras práticas relacionadas com o parto, são considerados como violência obstétrica.

No que se refere à formação médica, procedimentos como a cesariana fazem parte do aprendizado de estudantes de obstetrícia, alertando que, na prática, a cirurgia não é somente indicada em casos de risco para a mulher e para o bebê, mas também para ensino. $\mathrm{O}$ artigo de Souza $^{20}$ descreve situações em que mulheres são objetificadas em prol do treinamento de residentes em obstetrícia. Algumas práticas violentas observadas pela pesquisa foram: proibição de acompanhante (9,3\%), falhas no esclarecimento de dúvidas (16,3\%) e procedimentos obstétricos sem autorização/esclarecimentos (27,3\%) e episiotomia (25,5\%). De acordo com Hotimsky ${ }^{28}$, a socialização dos estudantes de medicina favorece o distanciamento dos alunos e dos pacientes, a naturalização das hierarquias sociais, assim como a 'coisificação' dos corpos, que passam a ser vistos como objeto de treinamento. Por outro lado, o artigo de Souza ${ }^{20}$ aponta um estudo que observou a inserção das disciplinas de humanidades na grade curricular do ensino em saúde no Brasil, sendo a temática da humanização do cuidado um dos eixos abordados. Contudo, os alunos não demonstraram interesse no tema, considerando 'desinteressante e dispensável'20, em parte pela forma na qual o assunto é abordado nas aulas.

Também é importante considerar a hierarquia entre os profissionais da medicina e enfermagem, que influencia diretamente na assistência prestada, pois restringe a atuação da enfermagem. Nesse sentido, o artigo de Oliveira e Penna ${ }^{21}$ aborda como o parto pode ser traumático, não só para a mulher como também para a equipe.

No modelo hospitalar brasileiro, a enfermagem é a categoria que dedica mais tempo aos cuidados da gestante, acompanhando-a em todos os momentos de sua internação. São as(os) enfermeiras(os), técnicas(os) e auxiliares de enfermagem que permanecem ao lado das usuárias, antes e depois de qualquer intervenção médica, monitorando a melhora ou piora do quadro de saúde, observando intercorrências e prestando cuidados que vão para além da técnica.

A enfermagem obstétrica, como premissa, forma profissionais nos moldes do Programa de Humanização do Pré-Natal (PHPN), logo, é inegável a contribuição para a mudança da prática obstétrica, seja por meio da produção científica, seja da assistência. Estudos apontados pelo artigo de Narchi ${ }^{29}$ comprovam que nenhum país conseguiu reduzir as taxas de mortalidade materna sem investir na formação de obstetrizes e enfermeiras obstetras, assim como inseri-las na atenção básica e nas instituições que atendem mulheres na fase gravídico-puerperal. Contudo, a visibilidade e a autonomia dessas profissionais ainda são um problema, sendo necessário o investimento na formação e no campo de atuação. Nesse sentido, a ampliação das Casas de Parto valorizaria o fenômeno do parto e nascimento na perspectiva fisiobiológica e social. As Casas de Parto funcionam como unidades autônomas, dispondo de recursos materiais e humanos, adequados para prestar a assistência humanizada para as mulheres e bebês. Geralmente, são construídas em convênio com unidades de referência próximas, e se caracterizam pelo aspecto de residência, ao invés de unidades hospitalares ${ }^{31}$. A humanização do parto depende da melhoria das relações entre os profissionais de saúde e as usuárias dos serviços. Para isso, são essenciais transformações significativas da formação e da valorização de novos saberes e práticas; aquisição de uma postura mais dialógica e horizontal da equipe com as pacientes; rediscussão do modelo excessivamente biológico da medicina e adoção de maior responsabilidade política e ideológica dos gestores, visando à retomada do protagonismo da mulher nos 
cenários supracitados 15,20,29.

\section{Aspectos socioculturais que envolvem a escolha da cesárea comumente conhecidos como a 'cultura da cesárea'}

Diante dos estudos e discussões abordadas, é possível entender o rechaço ao parto vaginal. Nas falas de algumas entrevistadas, esse é um evento incontrolável, sangrento, doloroso, arriscado. Ao mesmo tempo, muitas referem não se sentir capazes de parir naturalmente, referindo restrições corporais, como força física, tolerância à dor, altura ou tamanho do quadril como determinantes ${ }^{18}$. Logo, a cesárea surge como a solução de todos os problemas, naturalizando-se como a via mais segura de nascer, enquanto, muitas vezes, seu risco é ignorado e desconhecido.

Ao analisar os estudos selecionados, destaca-se, como pontos importantes das narrativas femininas, o medo da dor como a principal justificativa de cesárea a pedido ${ }^{13}$. Se, por um lado, o discurso dos profissionais de saúde alega a persuasão das mulheres na escolha da via do parto sob a alegação de que desejam a cesariana ou que não toleram a dor do parto vaginal, por outro, observam-se os discursos das mulheres sobre terem sua dor negligenciada ou de serem desrespeitadas durante o trabalho de parto ${ }^{13,22}$.

Entende-se que, em um contexto no qual existe o aprimoramento da técnica cirúrgica, analgésicos e anestésicos, a possibilidade de parir sem dor se torna sedutora, assim como a praticidade do parto cirúrgico para o obstetra. Diniz $^{30}$ afirma que a obstetrícia que se formou a partir do século XIX - exclusivamente por homens - oferecia a opção do apagamento por meio da sedação. Sendo assim, muitas mulheres, nesse período, pertencentes à classe média e alta, deram à luz inconscientes.

$\mathrm{O}$ artigo de Freire et $\mathrm{al.} .^{15}$, por sua vez, ressalta que é comum ouvir relatos de mulheres que se consideram incapazes de parir por via vaginal. Desconsideram ou desconhecem alternativas para o alívio da dor, como as práticas não farmacológicas incentivadas pela OMS: livre movimentação durante o trabalho de parto, massagens, banhos, acupuntura, musicoterapia, entre outras.

Consideram-se ainda, como método de alívio não farmacológico da dor, fatores externos como a presença de acompanhante familiar ou doula. A doula é quem orienta e assiste a nova mãe no parto e nos cuidados com bebê a partir de uma nova proposta de parto humanizado. Seu papel é oferecer conforto, encorajamento, tranquilidade, suporte emocional, físico e informativo. No entanto, muitas vezes, a mulher encontra resistência nas instituições ao solicitar a presença desses assistentes, apesar de ambos terem respaldo legal para acompanhar a parturiente ${ }^{31}$.

O artigo de Gama et al. ${ }^{19}$ aborda as representações e vivências de mulheres quanto à dor do parto normal, tanto no setor público quanto no privado. De acordo com as entrevistadas, a aceitação da dor como aspecto intrínseco do ato de parir auxilia no processo do trabalho de parto. Apesar da dor, as entrevistadas afirmam preferir o parto normal pela possibilidade de protagonizarem o nascimento de seus filhos, já que, na cesárea, a imobilização do parto e pós-parto imediato dificulta essa vivência. Por outro lado, o artigo de Barbosa et al. ${ }^{17}$ mostra que, entre as mulheres entrevistadas que não desejavam a cesárea, mas que por algum motivo a solicitaram, a maioria absoluta (93,9\%) o fez durante o trabalho de parto e/ ou parto, confirmando que a dor foi um fator determinante para a escolha.

\section{Considerações finais}

A presente revisão integrativa revelou questões sobre pré-natal, ensino profissional, violência obstétrica, tecnologia, direitos, modelos de atenção à saúde, taxa de mortalidade, acesso, entre outros. Isso mostra que não é possível recomendar uma única mudança pontual para que haja melhora na assistência ao parto, sendo 
necessário haver reformulações estruturais em todos os aspectos elencados, como na maneira de educar, prevenir, promover e respeitar a saúde, visando ao cuidado da gestante na perspectiva da humanização.

As representações das mulheres em relação à preferência da via de parto sofrem diversas influências, assim como suas possibilidades são limitadas por seus recursos. Durante a presente análise, foi possível observar diversos cenários: mulheres que gostariam de um parto vaginal e tiveram um parto violento; mulheres que, tamanha naturalização da relação assimétrica entre equipe e usuária, sequer sabiam que suas preferências poderiam ter sido consideradas no momento do parto; mulheres que puderam pagar, gostariam de um parto vaginal e não conseguiram; mulheres que puderam pagar e tiveram o parto que desejavam, seja ele qual for (cirúrgico ou natural); e mulheres que desejaram e conseguiram o atendimento que consideraram adequado e satisfatório.

O parto, antes um evento da vida da mulher, no âmbito do privado e sob os cuidados de outras mulheres, passa a ser medicalizado. Ou seja, passa a ser do domínio de médicos homens e realizado na instituição hospitalar. Esse fenômeno justifica a transição da mulher no cenário do parto, de protagonista a coadjuvante. Percebe-se, então, que essa problemática da atenção obstétrica no Brasil não é recente, e são muitos os aspectos que envolvem essa questão (culturais, econômicos, sociais e individuais).

Em geral, observa-se que os resultados do trabalho abordam contextos urbanos brasileiros, particularmente das regiões Sudeste, Sul e Centro-Oeste, sendo de extrema importância para o enriquecimento da discussão conhecer outros cenários de parto existentes, possibilitando avaliar o impacto da medicalização nas áreas rurais, desprovidas das facilidades tecnológicas e que contam com a atuação ainda que tímida - das parteiras tradicionais.

Os determinantes sociais mostram que as mulheres de renda mais baixa, atendidas no sistema público, percebem-se menos autônomas e mais vítimas de intervenções desnecessárias. Já as mulheres com maior renda, usuárias da rede suplementar, sentem a receptividade do médico diante da cesariana a pedido, porém não se sentem adequadamente informadas acerca das vias de parto durante seu acompanhamento. Essa falta de informação mencionada pelas mulheres caracteriza a qualidade da assistência prestada.

O medo da dor e o medo de sofrer violência na hora do parto apareceram nos discursos como fatores negativos do parto normal, o que reflete o impacto da violência obstétrica na saúde e reforça a importância da informação no processo de gestar e parir.

A cesariana destaca-se no cenário, trazendo a discussão sobre o modo 'normal' de nascer na sociedade moderna. Altas taxas de cesarianas a pedido ou baseadas em indicações não clínicas, como comodidade do agendamento e mitos, caracterizam o novo perfil obstétrico.

A visibilidade do tema é essencial para o aumento da produção científica e para a mobilização social, ambicionando que a violência obstétrica seja reduzida e passe a ser debatida publicamente, dentro das instituições, mídias e âmbito jurídico. Faz-se necessária uma postura pró-humanização do parto por parte da sociedade civil, gestores e entidades governamentais, que prezam pela dignidade ao parir e nascer, não só como um direito à saúde, mas também como um direito à vida.

No entanto, o Conselho Regional de Medicina do Rio de Janeiro publicou recentemente a Resolução no 293/2019, que proíbe os médicos do estado de aderirem a qualquer documento, seja o plano de parto ou similares, que "restrinjam a autonomia médica na tentativa de salvaguardar o bem-estar do binômio materno-fetal"32. Essa Resolução nos leva a pensar em um futuro não muito promissor para a humanização do parto e na necessidade de mais pesquisas sobre a autonomia das mulheres e o papel de cada ator envolvido no parto. Quando um plano de parto se torna ameaçador para a autonomia de um médico, percebe-se o quanto a atenção à saúde da mulher está comprometida pelo modelo vigente. 


\section{Colaboradoras}

Rocha NFF (0000-0002-2766-4275)* contribuiu substancialmente para a concepção, análise e interpretação dos dados. Ferreira J (0000-0002-7662-1773)* contribuiu significativamente para a análise, interpretação e revisão do artigo.

\section{Referências}

1. Patah LEM, Malik AM. Modelos de assistência ao parto e taxa de cesárea em diferentes países. Rev Saúde Pub. São Paulo. [internet]. 2011 [acesso em 2020 fev 26]; 45(1):185-194. Disponível em: http://www. scielo.br/scielo.php?script=sci_arttext\&pid=S0034$-89102011000100021 \& \operatorname{lng}=$ pt\&nrm=iso\&tlng=pt.

2. Souza JP. A mortalidade materna e os novos objetivos de desenvolvimento sustentável (2016-2030). Rev Bras Ginecol Obstet [internet]. 2015 [acesso em 2018 nov 21]; 37(12):549-51. Disponível em: http://www. scielo.br/scielo.php?script=sci_arttext\&pid=S0100$-72032015001200549 \& \operatorname{lng}=$ pt\&nrm=iso\&tlng=pt.

3. Diniz CSG. Gênero, saúde materna e o paradoxo perinatal. Rev. bras. crescimento desenvolv. hum. [internet]. 2009 [acesso em 2018 nov 30]; 19(2):313-326. Disponível em: http://pepsic.bvsalud.org/scielo.php?script=sci_arttext\&pid=S0104$-12822009000200012 \& \operatorname{lng}=$ pt\&tlng=pt.

4. Macedo JG, Arraes R. Autonomia da gestante na escolha de parto na realidade da prestação $4^{\circ}$ de assistência médico-hospitalar brasileira. In: Anais da $7^{\mathrm{a}}$. Jornada de Sociologia em Saúde, Curitiba/PR [internet]. 2013 [acesso em 2018 nov 8]. Disponível em: http://www.humanas.ufpr.br/portal/sociologiasaude/files/2013/12/AUTONOMIA-DA-GESTANTE-NA-ESCOLHA-DE-PARTO.pdf.
5. Leitão FJC. Autonomia da mulher em trabalho de parto. [dissertação] [internet]. Lisboa: Faculdade de Medicina, Universidade de Lisboa; 2010. 103 p. [acesso em 2018 dez 19]. Disponível em: https://core.ac.uk/ download/pdf/12422498.pdf.

6. Weidle WG, Medeiros CRG, Grave MTQ, et al. Escolha da via de parto pela mulher: autonomia ou indução? Cad. Saúde Colet. [internet]. 2014 [acesso em 2018 nov 12]; 22(1):46-53. Disponível em: http://www.scielo.br/scielo.php?pid=S1414-462 X2014000100046\&script=sci_abstract\&tlng=pt.

7. Silva DO, Silva GA, Andrade TS, et al. O desejo da mulher em relação à via de parto: uma revisão de literatura. Cadernos da Graduação [internet]. 2015 [acesso em 2018 nov 22]; 3(1):103-114. Disponível em: https:// periodicos.set.edu.br/index.php/fitsbiosaude/article/view/2582.

8. Hotimsky SN, Rattner D, Venancio SI, et al. O parto como eu vejo... ou como eu o desejo?: expectativas de gestantes, usuárias do SUS, acerca do parto e da assistência obstétrica. Cad. Saúde Pública [internet]. 2002 [acesso em 2018 nov 8]; 18(5):1303-1311. Disponível em: http://www.scielo.br/scielo.php?script=sci arttext\&pid=S0102-311X2002000500023\&lng=en.

Leão MRC, Riesco MLG, Schneck CA, et al. Reflexões sobre o excesso de cesarianas no Brasil e a autonomia 
das mulheres. Ciênc. Saúde Colet. [internet]. 2013 [acesso em 2018 out 8]; 18(8):2395-2400. Disponível em: http://www.scielo.br/scielo.php?script=sci_artt ext\&pid=S141381232013000800024\&lng=en.

10. Whittemore R. Combining evidence in nursing research: methods and implications. Nurs. Res. [internet]. 2005 [acesso em 2018 nov 5]; 54(1):56-62. Disponível em: https://www.ncbi.nlm.nih.gov/pubmed/15695940.

11. Crossetti MGO. Revisão integrativa de pesquisa na enfermagem: o rigor científico que lhe é exigido. Rev Gaúcha Enf. [internet]. 2012 [acesso em 2018 nov 6]; 33(2):8-13. Disponível em: http://www.scielo.br/pdf/ rgenf/v33n2/01.pdf.

12. Cesar JA, Sauer JP, Carlotto K, et al. Cesariana a pedido: um estudo de base populacional no extremo Sul do Brasil. Rev. Bras. Saude Mater. Infant. [internet]. 2017 [acesso em 2018 nov 8]; 17(1):99-105. Disponível em: http://www.scielo.br/scielo.php?script=sci_artt ext\&pid=S151938292017000100099\&lng=en.

13. Oliveira VJ, Penna CMM. Every birth is a story: process of choosing the route of delivery. Rev. Bras. Enferm. [internet]. 2018 [acesso em 2018 nov 8]; 71(3):1228-1236. Disponível em: http://www.scielo.br/scielo.php?script=sci_arttext $\&$ pid=S0034 $-71672018000901228 \& \operatorname{lng}=$ en.

14. Cabral FB, Hirt LM, Van der Sand ICP. Atendimento pré-natal na ótica de puérperas: da medicalização à fragmentação do cuidado. Rev. esc. enferm. USP [internet]. 2013 [acesso em 2018 nov 8]; 47(2):281287. Disponível em: http://www.scielo.br/scielo. php?script=sci_arttext\&pid=S00806234201300020 $0002 \& \operatorname{lng}=e n$.

15. Freire NC, Nunes IM, Almeida MS, et al. Parto normal ou cesárea? A decisão na voz das mulheres. Rev Baiana Enf. [internet]. 2011 [acesso em 2018 nov 9]; 25(3):237-247. Disponível em: https://portalseer.ufba. br/index.php/enfermagem/article/view/6027.

16. Pires D, Fertonani HP, Conill EM, et al. A influência da assistência profissional em saúde na esco- lha do tipo de parto: um olhar sócio antropológico na saúde suplementar brasileira. Rev. Bras. Saude Mater. Infant. [internet]. 2010 [acesso em 2019 nov 10]; 10(2):191-197. Disponível em: http://www. scielo.br/scielo.php?script=sci_arttext\&pid=S1519$-38292010000200006 \& \operatorname{lng}=\mathrm{en}$.

17. Barbosa GP, Giffin K, Angulo-Tuesta A, et al. Parto cesáreo: quem o deseja? Em quais circunstâncias?. Cad. Saúde Pública [internet]. 2003 [acesso em 2018 nov 8]; 19(6):1611-1620. Disponível em: http://www. scielo.br/scielo.php?script=sci_arttext\&pid=S0102$-311 X 2003000600006 \& \operatorname{lng}=\mathrm{en}$.

18. Nakano AR, Bonan C, Teixeira LA. A normalização da cesárea como modo de nascer: cultura material do parto em maternidades privadas no Sudeste do Brasil. Physis [internet]. 2015 [acesso em 2018 nov 11]; 25(3):885-904. Disponível em: http://www.scielo.br/scielo.php?script=sci_arttext\&pid=S01037331 2015000300885\&lng=en.

19. Gama AS, Giffin KM, Angulo-Tuesta A, et al. Representações e experiências das mulheres sobre a assistência ao parto vaginal e cesárea em maternidades pública e privada. Cad. Saúde Pública [internet]. 2009 [acesso em 2018 nov 15]; 25(11):2480-2488. Disponível em: http://www.scielo.br/scielo.php?script=sci arttext\&pid=S0102-311X2009001100017\&lng=en .

20. Souza AB, Silva LC, Alves RN, et al. Fatores associados à ocorrência de violência obstétrica institucional: uma revisão integrativa da literatura. Rev. Ciênc. Méd. [internet] 2016 [acesso em 2018 nov 14]; 25(3):115-128. Disponível em: http://pesquisa.bvsalud.org/portal/resource/pt/biblio-859888.

21. Oliveira VJ, Penna CMM. O discurso da violência obstétrica na voz das mulheres e dos profissionais de saúde. Texto Contexto Enferm. [internet]. 2017 [acesso em 2018 out 20]; 26(2):2-10. Disponível em: http://www.scielo.br/pdf/tce/v26n2/pt_0104-0707tce-26-02-e06500015.pdf.

22. Rangel VM, Camargo Jr KR. A negociação de um corpo com dor: racionalidade biomédica na dinâmica ritualizada do trabalho de parto hospitalar. Physis [internet]. 
2016 [acesso em 2018 out 8]; 26(4):1293-1310. Disponível em: http://www.scielo.br/scielo.php?script=sci arttext\&pid=S0103-73312016000401293\&lng=en .

23. Ferrari J. A autonomia da gestante e o direito pela cesariana a pedido. Rev Bioética [internet]. 2009 [acesso em 2018 out 15]; 17(3):473-495. Disponível em: http://revistabioetica.cfm.org.br/index.php/revista_bioetica/article/viewFile/512/513.

24. Andrezzo HFA. O desafio do direito à autonomia: Uma experiência de Plano de Parto no SUS. [dissertação] [internet]. São Paulo: Faculdade de Saúde, Universidade de São Paulo; 2016. 111 p. [acesso em 2018 dez 10]. Disponível em: http://www.teses.usp.br/teses/ disponiveis/ 6/6136/tde-07112016141429/publico/ HalanaFariaDeAguiarAndrezzo.pdf.

25. Diniz CSG. Entre a técnica e os direitos humanos: possibilidades e limites da humanização da assistência ao parto. [tese] [internet]. São Paulo: Faculdade de Medicina, Universidade de São Paulo; 2001. 255 p. [acesso em 2018 dez 5]. Disponível em: http://bases.bireme. br/cgi-bin/wxislind.exe/iah/online/?IsisScript=iah/ iah.xis\&src $=$ google $\&$ base $=$ LILACS\&lang $=$ p\&nextAc tion=lnk\&exprSearch=443320\&indexSearch=ID.

26. Oliveira VJ. O sensível e o insensível na sala de parto: interdiscursos de profissionais de saúde e mulheres. [tese] [internet]. Belo Horizonte: Escola de Enfermagem, Universidade Federal de Minas Gerais; 2016. 160 p. [acesso em 2020 jun 11]. Disponível em: https://pesquisa.bvsalud.org/portal/resource/pt/ bde-31071.

27. Porto AMF, Amorim MMR, Souza ASR. Assistência do primeiro período do trabalho de parto baseada em evidências. Femina [internet]. 2010 [acesso em 2018 dez 15]; 38(10):527-537. Disponível em: http://bhpelopartonormal.pbh.gov.br/estudos_cientificos/arquivos/artigo_femina_assistencia_ao_parto_parte_I.pdf.

28. Hotimsky SN. A violência institucional no parto no processo de formação médica em obstetrícia. In: En- contro Nacional de Antropologia do Direito; 2009 ago 21; São Paulo. São Paulo: USP; 2009. [acesso em 2020 jun 11]. Disponível em: https://www.researchgate.net/publication/268425794_A_violencia_institucional_no_parto_no_processo_de_formacao_medica_em_obstetricia.

29. Narchi NZ, Cruz EF, Gonçalves R. O papel das obstetrizes e enfermeiras obstetras na promoção da maternidade segura no Brasil. Ciênc. Saúde Colet. [internet]. 2013 [acesso em 2018 nov 8]; 18(4):1059-1068. Disponível em: http://www.scielo.br/scielo.php?script=sci arttext\&pid=S141381232013000400019\&lng=en.

30. Diniz CSG. Assistência ao parto e relações de gênero: elementos para uma releitura médico-social. [dissertação] [internet]. São Paulo: Faculdade de Medicina, Universidade de São Paulo; 1997. 209 p. [acesso em 2018 dez 15]. Disponível em: http://bases.bireme.br/ cgi-bin/wxislind.exe/iah/online/?IsisScript=iah/iah. xis\&src $=$ google $\&$ base $=$ LILACS\&lang $=p \&$ nextAction $=$ lnk\&exprSearch=478013\&indexSearch=ID.

31. Knobel R. Métodos para alívio da dor no trabalho de parto [internet]. Amigas do Parto. $2004 \mathrm{fev}$ 14 [acesso em 2019 jan 20]. Disponível em: http:// www.amigasdoparto.org.br/2 007/index.php?Item $\mathrm{id}=75 \& \mathrm{id}=252 \&$ option $=$ com_c ontent $\&$ task=view.

32. Conselho Regional de Medicina do Rio de Janeiro. Resolução no 293 de 23 de janeiro de 2019. Proibição de adesão, por parte de médicos, a quaisquer documentos, dentre eles o plano de parto ou similares, que restrinjam a autonomia médica na adoção de medidas de salvaguarda do bem estar e da saúde para o binômio materno-fetal. Diário Oficial do Estado do Rio de Janeiro. 6 Fev 2019. [acesso em 2020 jun 11]. Disponível em: https://www.cremerj.org.br/resolucoes/exibe/resolucao/1390

Recebido em 02/06/2019

Aprovado em 29/02/2020

Conflito de interesses: inexistente

Suporte financeiro: não houve 